\title{
Review: sucrose reduces crying during painful procedures in newborn infants
}

\author{
Stevens B, Taddio A, Ohlsson A, et al. The efficacy of sucrose for relieving procedural pain in neonates-a systematic review and \\ meta-analysis. Acta Paediatr 1997 Aug;86:837-42.
}

\section{Question}

Is sucrose effective and safe for reducing pain during procedures in newborn infants?

\section{Data sources}

Published studies of any language were identified using Medline (1966-95), Embase (1993-5), and Reference Update (1995-6). Search terms included infant/newborn, pain, analgesia, and sucrose. Recent neonatal and pain journals, conference proceedings, bibliographies, and personal files were hand searched.

\section{Study selection}

Studies were selected if they were blinded randomised controlled trials; the treatment included sucrose; the pain stimulus was a common medical procedure; outcomes were behavioural, physiological, hormonal, or metabolic responses to pain; and the study population was term or preterm neonates.

\section{Data extraction}

3 independent raters evaluated studies for methodological quality (eg, randomisation, double blinding, and accounting for dropouts). Data were extracted on study design, sample size and characteristics, intervention (including dosage), type of painful procedure, outcomes, results, study quality score, and study acceptability for meta-analysis. Efficacy estimates were quantified for different dosages of sucrose $(0.18 \mathrm{~g}, 0.24 \mathrm{~g}, 0.48 \mathrm{~g}$ or $0.50 \mathrm{~g}$, and $1.0 \mathrm{~g}$ ) and water (placebo control). The main outcome was percentage of time spent crying for 3 minutes after the painful procedure began or ended.

\section{Main results}

Data from 5 of 13 studies which met the criteria for inclusion were included in the meta-analysis ( $\mathrm{n}=271$ newborn infants). All but 1 of the 5 studies involved full term infants; 3 used heelstick as the painful procedure, 1 venipuncture, and 1 examined heelstick and circumcision. Meta-analysis was done using a random effects model. The proportion of time spent crying for sucrose dosages of $0.24 \mathrm{~g}, 0.48 \mathrm{~g}$ or $0.50 \mathrm{~g}$, and $1.0 \mathrm{~g}$ was lower than the proportion of time spent crying for $0.18 \mathrm{~g}$ sucrose or for water $(\mathrm{p}=<0.001)$. No differences in the proportion of time spent crying were found between dosages of $0.24 \mathrm{~g}, 0.48 \mathrm{~g}$ or $0.50 \mathrm{~g}$, or $1.0 \mathrm{~g}$ (table). No differences were found for term and preterm newborn infants, and no adverse effects were reported in any study.

\section{Conclusion}

Sucrose reduces the proportion of time spent crying during painful procedures in newborn infants.

Proportion of time newborn infants spent crying during 3 minutes after a painful procedure

\begin{tabular}{llll}
\hline Solution and dosage & $\begin{array}{l}\text { Sample } \\
\text { size }\end{array}$ & $\begin{array}{l}\text { Percentage of time } \\
\text { spent crying }\end{array}$ & 95\% CI \\
\hline Water & 95 & 63.3 & 40.1 to 86.4 \\
Sucrose $0.18 \mathrm{~g}$ & 16 & 77.3 & 52.8 to 91.2 \\
Sucrose $0.24 \mathrm{~g}$ & 73 & 38.0 & 22.4 to 53.6 \\
Sucrose $0.48 \mathrm{~g}$ or $0.50 \mathrm{~g}$ & 72 & 23.6 & 12.0 to 34.7 \\
Sucrose $1.0 \mathrm{~g}$ & 15 & 25.0 & 9.9 to 50.3 \\
\hline
\end{tabular}

Sources of funding: National Institutes of Health and Fonds de la Recherche en Sante du Quebec.

For article reprint: not available.

\section{Commentary}

This systematic review by Stevens et al evaluates the efficacy of a nonpharmacological intervention using the rigorous methods normally used to test pharmacological interventions, and reports positive results. The conclusions are based on evidence from 13 placebo controlled trials which were identified from a thorough and clearly described search. Data from the primary studies were clearly presented in table format, and 12 of 13 trials showed $\geqslant 1$ difference for at least 1 outcome in favour of sucrose over placebo. Meta-analysis showed a positive effect for sucrose in dosages of $\geqslant 0.24 \mathrm{~g}$, but only 5 of the 13 trials were included in the analysis. Over $50 \%$ of the eligible trials could not be included in the meta-analysis because of methodological problems and problems associated with appraising and extracting information from primary studies. ${ }^{1}$ These problems should be considered when drawing conclusions about the effectiveness of su- crose. For example, studies varied in sample size, blinding, outcome measures, and methodological quality. Surprisingly, the authors were able to include data from 2 abstracts in the analysis. Abstracts usually do not provide sufficient extractable data for meta-analysis. ${ }^{2}$

The authors also noted the difficulties associated with the selection of reliable outcome measures for assessing pain in newborn infants (ie, how can we be sure that duration of crying is a reliable measure of pain?). Adverse effects were rarely documented, making it difficult to comment on potential short and long term risks associated with sucrose feeding.

This review shows that $2 \mathrm{ml}$ of $12 \%$ sucrose reduces crying when given to newborn infants approximately 2 minutes before beginning a painful procedure. Given that sucrose is readily available and relatively inexpensive, nurses who care for newborn infants may want to consider this option when giving routine painful proce- dures such as heelsticks. Other solutions (eg, commercially available milk) have also been shown to reduce crying during painful procedures, ${ }^{3}$ and should therefore also be considered. Of course, parents, particularly mothers who are exclusively breast feeding, should always be consulted and their preferences respected. Further research on this intervention should document short and long term adverse effects, and attempt to clarify issues about the reliable measurement of pain in infants.

$$
\begin{array}{r}
\text { Dawn Carroll, SRN, BA(Hons) } \\
\text { Senior Research Nurse } \\
\text { University of Oxford } \\
\text { Honorary Research Fellow } \\
\text { RCN Institute } \\
\text { Oxford, UK }
\end{array}
$$

1 McQuay H, Moore A. An evidence-based resource for pain. Oxford: Oxford University Press, in press.

2 L'Abbé KA, Detsky AS, O'Rourke K. Metaanalysis in clinical research. Ann Intern Med 1987;107:224-33.

3 Blass EM. Milk-induced hypoalgesia in human newborns. Pediatrics 1997;99:825-9. 